\title{
Artemisia afra and hypertension
}

\begin{abstract}
Artemisia annua and Artemisia afra have shown a high efficacy in many in vivo and in vitro trials against tropical diseases. The plants also have a hypotensive effect. This paper proposes several hypotheses to explain this property.
\end{abstract}

Keywords: hypertension, scopoletin, Artemisia afra, nitric oxide, potassium, blood pressure, malaria
Volume 7 Issue $6-2019$

\section{Pierre Lutgen}

IFBV-BELHERB, Luxembourg

Correspondence: Pierre Lutgen, IFBV-BELHERB, BP 98 L-6905, Niederanven, Luxembourg, Email lutgenp@gms.lu

Received: October 27, 2019 | Published: December 06, 2019

\section{Introduction}

Hypertension is a major healthcare problem afflicting nearly 50 million individuals in the United States alone. Hypertension increases the risk of stroke, heart disease, kidney failure and eventually malaria. Artemisia plants have shown a remarkable effect against several tropical diseases: malaria, schistosomiasis, Chagas, leishmaniasis. ${ }^{1-7}$

Considering all these data it would not be surprising to find that these diseases and Artemisia plants also have an effect on some metabolic and bodily functions. ${ }^{8}$ Epidemiological links between malaria parasitaemia and hypertension. A recent paper from South Africa reports a strong antihypertensive effect of Artemisia afra. The extract had its greatest antihypertensive effect at 2 and 4 hours post treatment, while the effect of Leonotis leonuras, another plant used for its antihypertensive properties, and of Furosemide were weak at its best. The authors also found that the Artemisia afra plant extract was non-toxic with LD50 values greater than $5000 \mathrm{mg} / \mathrm{kg}$. ${ }^{9,10}$ Similar hypotensive effects have been noticed in other Artemisia plants, for example, Artemisia herba alba ${ }^{11,12}$ or Artemisia Persia ${ }^{13}$ or Artemisia copa in Argentina ${ }^{14}$ and even Artemisia vulgaris. ${ }^{15}$

Artemisia maritima was investigated in Tunesia, measuring the effect of the water-boiled extract of Artemisia campestris on human hemodynamic system. To do so, the blood pressure parameters of two groups of adult volunteers were recorded before and each 15 minutes after drinking $20 \mathrm{ml}$ of the boiled extract (20g of dried leaves / $1 \mathrm{~L}$ of water). The diastolic pressure and heart rate significantly diminished following the treatment, the systolic pressure did not significantly change. ${ }^{16}$ Some studies have shown a link between inflammation and hypertension. Human data support previous evidence from animal studies that the cytokine IL-6 plays a role in hypertension. Patients with pulmonary arterial hypertension had significantly elevated IL-1 $\beta$ and IL-6 in the serum. ${ }^{17-19}$ A study from the University of Louvain has shown that Artemisia annua infusions reduce IL-6 and IL-8 cytokines. For some unknown reasons the plant from Luxembourg compared with 6 others had the strongest effect. In South Africa Artemisia afra is a well-known herbal medicine used for various inflammatory conditions..$^{20-23}$

Hypertensives have higher interleukin-6 as per a study from Boston as shown by this graph

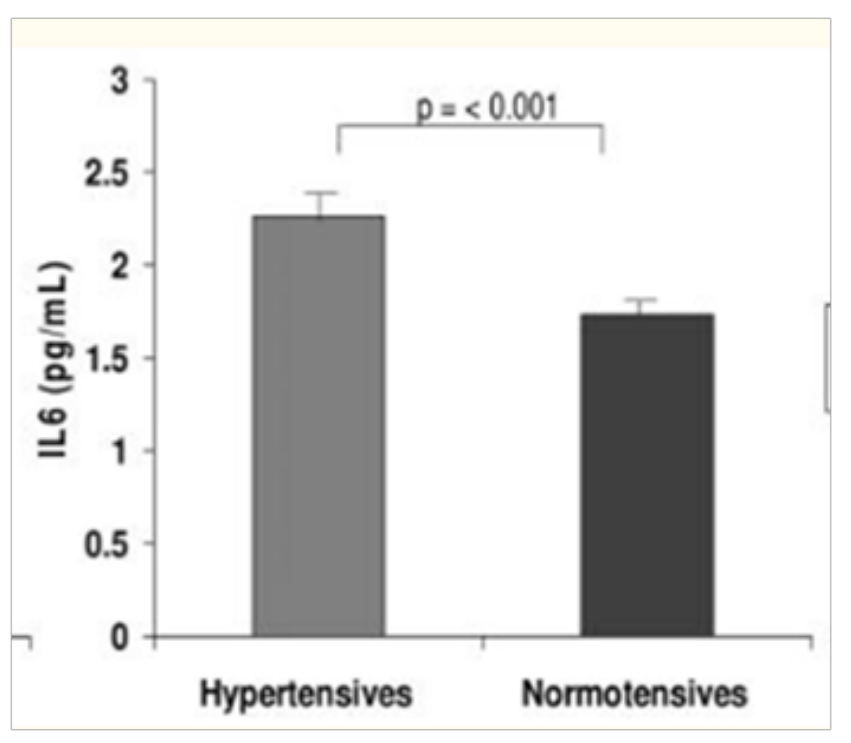

\section{The scopoletin hypothesis}

Already in 1983, the plausible mechanisms of the hypotensive effect of scopoletin, a coumarin have been investigated in vivo and in vitro. The results obtained show that scopoletin probably produces hypotension in laboratory animals through (a) its smooth muscle relaxant activity, which means it presumably dilates blood vessels; and (b) by acting as a non-specific spasmolytic agent. ${ }^{24}$ The same hypothesis was developed in a paper from Ghana. Their results suggest that aqueous extracts of Artemisia afra are potentially useful for the management of hypertensive condition..$^{25}$ The blood pressure lowering effect of scopoletin is well described in a paper from Indonesia (Figure 1). ${ }^{26}$

Scopoletin was one of the first major constituents detected in Artemisia afra some 100 years ago. ${ }^{27}$ Artemisia afra is rich in scopoletin $0.10 \mathrm{mg} / \mathrm{gDW}$ vs $0.05-0.06$ in Artemisia annua. ${ }^{28}$ The Noni fruit which is rich in scopoletin is reputed for its hypotensive activities. $^{29}$ 


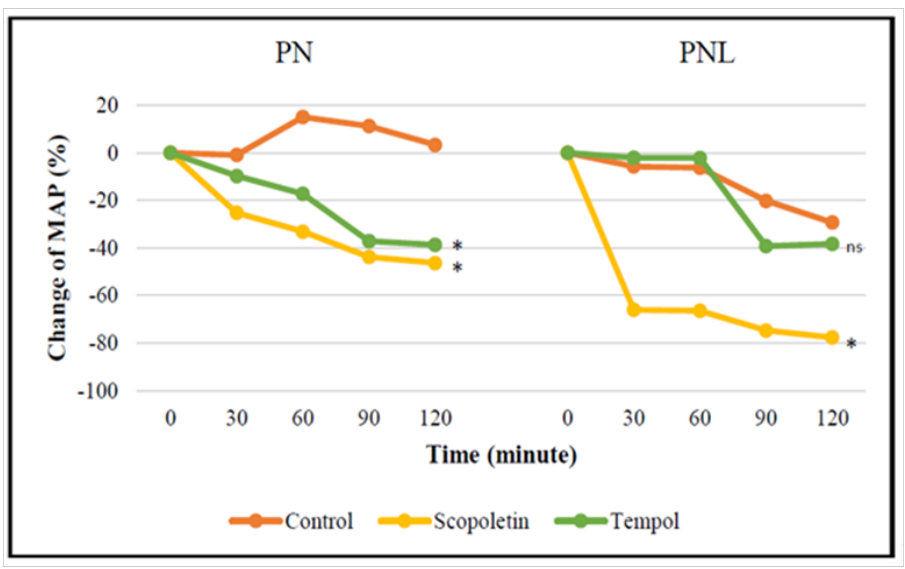

Figure I Comparative effect of the treatment to MAP (mean arterial pressure) on different hypersensitive models during 120 minutes of observation ( $P N=$ group treated with prednisone $+\mathrm{Nacl}$; $\mathrm{PNL}=$ group treated with prednisone $+\mathrm{Nacl}+\mathrm{L}-\mathrm{NAME}$; data with negative $(-)$ values indicate the decrease of the parameter; ${ }^{*} \mathrm{p}<0.05$ and $\mathrm{ns}=$ not significant comparative to control; $\mathrm{n}=\mid 8$ ).

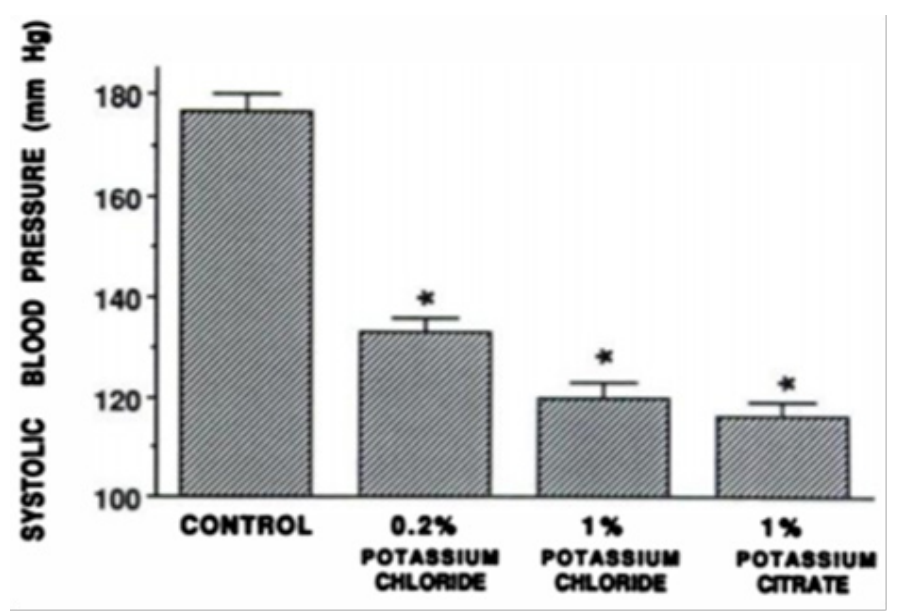

Figure 2 Changes in systolic blood pressure in DOCA-salt hypertensive rats receiving $1 \%$ sodium chloride to drink.

\section{The arginine hypothesis}

Reduced nitric oxide (NO) bioactivity represents prominent pathophysiological abnormalities associated with hypertensive cardiovascular disease. L-arginine serves as the principal substrate for vascular NO production. Several studies demonstrate a beneficial effect of chronic or acute L-arginine supplementation. One of the possible mechanisms is vascular dilatation..$^{30,31} \mathrm{~A}$ meta-analysis included 11 randomized, double-blind, placebo-controlled trials involving 387 participants with oral L-arginine intervention ranging from 4 to $24 \mathrm{~g} / \mathrm{d}$. Compared with placebo, L-arginine intervention significantly lowered systolic BP by $5.39 \mathrm{~mm} \mathrm{Hg}$ diastolic BP by 2.66 $\mathrm{mm} \mathrm{Hg}$. There is indeed an abundant literature on this topic. ${ }^{32-36}$

Suppression of plasma nitric oxide (NO) concentration may be involved in the pathogenesis of cerebral malaria, according to the authors of a combined USA/Tanzanian study. Tanzanian children with cerebral malaria had significantly decreased plasma and urine nitrogen oxide concentrations compared with those with symptom- free parasitaemia and healthy controls. In-vitro work has also previously supported an anti-plasmodial role for endogenous NOrelated compounds. ${ }^{37} \mathrm{~A}$ recent study from Ukraine has analyzed the amino acid content in some 8 plants of the Artemisia subgenus found that they are all 5 to 10 times richer in arginine than other herbs or vegetables, with $A$. annua top-ranking $(2 \mathrm{~g} / 100 \mathrm{~g}) .^{38}$ This is in line with the results of Brisibe and Ferreira who also find $2 \mathrm{~g} / 100 \mathrm{~g}$ for Artemisia annua. Onions contain $0.10 \mathrm{~g} / 100 \mathrm{~g}$, garlic $0.63 \mathrm{~g} / 100$ and milk $0.2 \mathrm{~g} / 100 \mathrm{~g} .{ }^{39}$

\section{The potassium hypothesis}

Epidemiologic, experimental, and clinical studies have shown that potassium is an important regulator of blood pressure. ${ }^{40-43}$ Potassium intake has been shown to have a beneficial effect on the cardiovascular system. Increased potassium swells endothelial cells and modifies endothelial cell stiffness. ${ }^{44}$ Artemisia plants are very rich in potassium and contain virtually no sodium. The work of Brisibe and Ferreira has found this for Artemisia annua (E A Brisibe, op.cit.). Similar high concentrations of potassium have been found in Artemisia herba alba, and a barely detectable presence of sodium. ${ }^{45}$

\section{The role of artemisinin: beneficial or detrimental?}

It is strange that Artemisia annua or artemisinin are never mentioned to have a hypotensive effect. An increasing body of evidence suggests that oxidative stress, which results in an excessive generation of reactive oxygen species (ROS), has a key role in the pathogenesis of hypertension. These reactive oxygen species include superoxide, hydroxyl radical, hydrogen peroxide, peroxynitrite, hypochlorous acid and artemisinin. These strong oxidants also kill the plasmodium parasite. ${ }^{46}$ The pro-oxidant activity of artemisinin is simply too potent and rapid for wild-type parasites to combat and survive ${ }^{47}$ Clinical studies demonstrated increased ROS production in patients with essential hypertension, renovascular hypertension, malignant hypertension. ${ }^{48}$

\section{Malaria and hypertension}

Some studies show that there are indications of a potentially dangerous link between high rates of malaria and high blood pressure, and they are urging more research in hopes of better addressing harmful effects of hypertension in malaria-stricken areas. Some studies find that malaria raises blood pressure. ${ }^{49,50}$ Some other studies find that malaria lowers blood pressure. ${ }^{50,51}$ But the effect of high blood pressure on malaria immunity or sensitivity has barely been studied.

\section{Conclusion and prospects}

This obviously is a new research field of a high complexity. The effect of Artemisia plants on hypertension is well described in the scientific literature. But we are lacking an understanding of the mechanism for the hypotensive effects as we still do for the antimalarial effects. It is a polytherapy and each attempt to isolate one molecule and to claim that the efficacy of the plant is due to this monotherapy has failed. This is for example in malaria infections the case for quinine and its derivative chloroquine or for artemisinin and its derivative artesunate. Even for artemisinin alone the mechanism of action has not been fully elucidated and five hypotheses are still in debate. 


\begin{tabular}{ll}
\hline $\begin{array}{l}\text { Artemisia constituents } \\
\text { which have been reviewed in } \\
\text { this paper }\end{array}$ & $\begin{array}{l}\text { Artemisia constituents } \\
\text { which deserve further } \\
\text { investigation }\end{array}$ \\
\hline Scopoletin & $\begin{array}{l}\text { Essential oils } \\
\text { Potassium }\end{array}$ \\
Polycyclic triterpenes \\
Arteminine & Anthocyanidins \\
& Saponins \\
\hline
\end{tabular}

The interplay between molecules or minerals in a plant can be synergistic or antagonistic. What is found in vitro often does not work in vivo. The aim of our research team is to better understand these interactions, and explanations found in a field like hypertension might also apply to malaria or other tropical diseases. We are presently working with 3 universities in Belgium and 8 universities in Africa on the topic of plant polytherapy. Several laboratories and medical teams have studied the eventual toxicity of Artemisia annua or Artemisia afra and their interaction with other drugs. A review of all the scientific papers on these topics has been published. Nobody was able to detect any acute or chronic toxicity for the consumption of these plants, which have been utilized since millenaries without any side effect.

\section{Acknowledgments}

None.

\section{Conflicts of interest}

Author declares that there is no conflict of interest.

\section{References}

1. Munyangi J, Cornet-Vernet L, Idumbo M, et al. Artemisia annua and Artemisia afra tea infusions vs. artesunate-amodiaquine (ASAQ) in treating Plasmodium falciparum malaria in a large scale, double blind, randomized clinical trial. Phytomedicine. 2019;57:49-56.

2. Daddy NB, Kalisya LM, Bagire PG, et al. Artemisia annua dried leaf tablets treated malaria resistant to ACT and iv artesunate: case reports. Phytomedicine. 2017;32:37-40.

3. Onimus M, Carteron S, Lutgen P. The Surprising Efficiency of Artemisia annua Powder Capsules. Med Aromat Plants. 2013;2(3):1-4.

4. Kansango TC, Lutgen P. In Vivo Trials on The Therapeutic Effects of Encapsulated Artemisia annua and Artemisia afra. GJRA. 2016;5(6):228-234

5. Munyangi J, Cornet-Vernet L, Idumbo M, et al. Effect of Artemisia annua and Artemisia afra tea infusions on schistosomiasis in a large clinical trial. Phytomedicine. 2018;51:233-240.

6. Morgado MB, Buiza JI, Lutgen P, et al. Activity of Artemisia annua infusions on epimastigotes of Trypanosoma cruzi. Enferm Infecc Microbiol Clin. 2017;35(6):390-392.

7. Mesa LE, Vasquez D, Lutgen P, et al. In vitro and in vivo antileishmanial activity of Artemisia annua L. leaves powder and its potential usefulness in the treatment of uncomplicated cutaneous leishmaniasis in humans. Rev Soc Bras Med. 2017;50(1):52-60.

8. Volpe M, Battistoni A. An evolutionary rebus: the complex link between malaria and hypertension. J Hypertens. 2019;37(7):1344-1346.
9. Mungho TC, Tobela GE, Ngwenchi B. Acute Toxicity and Antihypertensive Effects of Artemisia afra and Leonotis leonurus in Spontaneously Hypertensive Rats. Research Journal of Biotechnology. 2018;13(1):20-25.

10. Ben-Nasr H, Ali Ben MA, Salama M, et al. Potential Phytotherapy use of Artemisia Plants: Insight for Anti-Hypertension. Journal of Applied Pharmaceutical Science. 2013;3(5):120-125.

11. Zeggwagh NA, Farid O, Michel JB, et al. Cardiovascular effect of Artemisia herba alba aqueous extract in sponstaneously hypertensive rats. Methods Find Exp Clin Pharmacol. 2008;30(5):375-381.

12. Skiker M, Mekhfi H, Aziz M, et al. Artemisia herba-alba Asso relaxes the rat aorta through activation of NO/cGMP pathway and K(ATP) channels. J Smooth Muscle Res. 2010;46(3):165-174.

13. Esmaeili F, Sepehri G, Moshtaghi-Kashanian GR, et al. The effect of acute administration of Artemisia persia extracts on arterial blood pressure and heart rate in rats. Am J Appl Sci. 2009;6(5):843-847.

14. Gorzalczany S, Moscatelli V, Ferraro G. Artemisia copa aqueous extract as vasorelaxant and hypotensive agent. $J$ Ethnopharmacol. 2013;148(1):56-61.

15. Tigno XT, de Guzman F, Flora AM. Phytochemical analysis and hemodynamic actions of Artemisia vulgaris L. Clin Hemorheol Microcirc. 2000;23(2-4):167-175.

16. Ben-Nasr H, Salama M, Ksouda K, et al. Hemodynamic effects of aqueous extract of Artemisia campestris in adult men. Journal of Applied Pharmaceutical Science. 2014;4(4):38-42.

17. Chamarthi B, Williams GH. Inflammation and hypertension: the interplay of interleukin-6, dietary sodium, and the renin-angiotensin system in humans. Am J Hypertens. 2011;24(10):1143-1148.

18. De Miguel C, Rudemiller NP, Abais JM, et al. Inflammation and hypertension: new understandings and potential therapeutic targets. Curr Hypertens Rep. 2015;17(1):507.

19. Tanase DM, Gosav EM, Radu S, et al. Arterial Hypertension and Interleukins: Potential Therapeutic Target or Future Diagnostic Marker? International Journal of Hypertension. 2019;2019:3159283.

20. Melillo de Magalhães P, Dupont I, Hendrickx A, et al. Anti-inflammatory effect and modulation of cytochrome P450 activities by Artemisia annua tea infusions in human intestinal Caco-2 cells. Food Chemistry. 2012;134(2):864-871

21. Hoosen M, John Pool E. An in vitro study to eleucidate the effect of Artemisia afra on immune pathways. International Journal of Human and Health Sciences. 2019;3(3):134-145.

22. Alesaeidi S, Miraj S. A Systematic Review of Anti-malarial Properties, Immunosuppressive Properties, Anti-inflammatory Properties, and Anti-cancer Properties of Artemisia Annua. Electron Physician. 2016;8(10):3150-3155.

23. Seong Hun Jeong, Jisu Kim, Hyeyoung Min. In vitro anti-inflammatory activity of the Artemisia montana leaf ethanol extract in macrophage RAW 264.7 cells. Food and Agricultural Immunology. 2018;29(1):688698.

24. Ojewole JAO, Adesina SK. Mechanism of the Hypotensive Effect of Scopoletin Isolated from the Fruit of Tetrapleura tetraptera. Planta Med. 1983;49(9):46-50.

25. Guantai AN, Adda-Mensah I. Cardiovascular effect of Artemisia afra and its Constituents. Pharmaceutical Biology. 1999;37(5):351-356.

26. Armenia A, Hidayat R, Meliani M, Yuliandra Y. Blood pressure lowering effect of scopoletin on oxidative stress-associated hypertensive rats. $J$ Res Pharm. 2019;23(2):249-258. 
27. Goodson JA. The Constituents of the Flowering Tops of Artemisia afra Jacq. Biochemical Journal. 1922;16(4):489-493.

28. Munyangi J, Cornet-Vernet L, Idumbo M, et al. Effect of Artemisia annua and Artemisia afra tea infusions on schistosomiasis in a large clinical trial. Phytomedicine. 2018;51:233-240.

29. Inada AC, Figueiredo FS, Freitas KC, et al. Morinda citrifolia (Noni) and its potential. Nutrients. 2017;9(6):540.

30. Gokce N. L-arginine and hypertension. J Nutr. 2004;134(10 Suppl):2807S-2811S.

31. Vasdev S, Gill V. The antihypertensive effect of arginine. Int J Angiol. 2008;17(1):7-22.

32. Dong JY, Qin LQ, Zhang Z, et al. Effect of oral L-arginine supplementation on blood pressure: a meta-analysis of randomized, double-blind, placebo-controlled trials. Am Heart J. 2011;162(6):959965.

33. Bode-Boger SM, Muke J, Surdacki A, et al. Oral L-arginine improves endothelial function in healthy individuals older than 70 years. Vasc Med. 2003;8(2):77-81.

34. Moss MB, Brunini TM, Soares De Moura R, et al. Diminished L-arginine bioavailability in hypertension. Clin Sci (Lond). 2004;107(4):391-397.

35. Lekakis JP, Papathanassiou S, Papaioannou TG, et al. Oral L-arginine improves endothelial dysfunction in patients with essential hypertension. Int J Cardiol. 2002;86(2-3):317-323.

36. Gokce N. L-arginine and hypertension. J Nutr. 2004;134(10 Suppl):2807S-2811S.

37. Hopkins KD. Nitric oxide may have role in cerebral malaria. Exp Med. 1996;348(9026):533.

38. Ochkur V, Kovaleva AM, Ya S Kolesnik. Amino-Acid Composition of Subgenus Artemisia Herbs. Chemistry of Natural Compounds. 2013;49(3):589-591.

39. Brisibe EA, Ferreira JFS. Nutritional characterization and antioxidant capacity of different tissues of Artemisia annua. Food Chemistry. 2009;115(4):1240-1246.
40. Krishna GG. Effect of potassium intake on blood pressure. J Am Soc Nephrol. 1990;1(1):43-52.

41. He FJ, Markandu ND, Coltart R, et al. Effect of short-term supplementation of potassium chloride and potassium citrate on blood pressure in hypertensives. Hypertension. 2005;45(4):571-574.

42. Kihara M, Fujikawa J, Ohtaka M, et al. Interrelationships between blood pressure, sodium, potassium. serum cholesterol, and protein intake In Japanese. Hypertension. 1984;6(5):736-742.

43. Kasteboot H, Joossens JV. Relationship of serum sodium. potassium. calcium and phosphorous with blood pressure. Belgium interuniversity research on nutrition and health. Hypertension. 1988;12(6):594-599.

44. Oberleithner $\mathrm{H}$, Callies $\mathrm{C}$, de Wardener HE. Potassium softens vascular endothelium and increases nitric oxide release. PNAS. 2009;106(8):2829-2834.

45. Fenardji F, Klur M. Contribution to the study of white wormwood (Artemisia herba alba L.). Rev Elev Méd vét Pays Trop. 1974;2(2):203206.

46. Rodrigo R, González J, Paoletto F. The role of oxidative stress in the pathophysiology of hypertension. Hypertens Res. 2011;34(4):431-440.

47. Fairhurst RM, Dondorp AM. Artemisinin-resistant Plasmodium falciparum malaria. Microbiol Spectr. 2016;4(3).

48. Touyz RM. Reactive oxygen species, vascular oxidative stress, and redox signaling in hypertension: what is the clinical significance? Hypertension. 2004;44(3):248-252.

49. Etyang AO, Smeeth L, Cruickshank JK, et al. The Malaria-High Blood Pressure Hypothesis. Circulation Research. 2016;119(1):36-40.

50. Eze IC, Bassa FK, Essé C, et al. Epidemiological links between malaria parasitaemia and hypertension: findings from a population-based survey in rural Côte d'Ivoire. Journal of Hypertension. 2019;37(7):1384-1392.

51. Anigbogu CN, Olubowale OA. Effects of Malaria on Blood Pressure, Heart Rate, Electrocardiogram and Cardiovascular Response to Change in Posture. Nigerian Quarterly Journal of Hospital Medicine. 2002;12(1):17-20. 